\title{
PSICOLOGIA DA SAÚDE: O ACOLHIMENTO HUMANIZADO NA SALA DE OBSERVAÇÃO DE UMA UNIDADE PRÉ-HOSPITALAR
}

\author{
Cali Rodrigues de Freitas \\ Cybele Carolina Moretto \\ Universidade Paulista, Sorocaba-SP, Brasil
}

\begin{abstract}
RESUMO
Este relato de experiência teve como objetivo apresentar as intervenções e os resultados de um estágio curricular em Psicologia da Saúde realizado em uma unidade préhospitalar. Os atendimentos psicológicos abrangeram os seguintes participantes: pacientes, familiares, acompanhantes e equipe técnica com faixas etárias entre sete e 82 anos. O instrumento utilizado foi a entrevista psicológica diagnóstica. Os resultados apontaram que as pessoas atendidas receberam de forma positiva o cuidado global que lhes foi destinado por meio da inserção da estagiária na sala de observação. Nas muitas ocasiões em que houve intervenção psicológica, as pessoas atendidas tiveram seu sofrimento amenizado, assim como uma maior reflexão sobre o "estar doente". Configurou-se, dessa maneira, uma atuação humanizada para com as pessoas atendidas em um ambiente hospitalar, onde, por vezes, o corpo físico tem prevalência no que se refere aos cuidados despendidos e as outras dimensões prescindem de atenção. Humanizar significou beneficiar as pessoas atendidas com um cuidado integral.

Palavras chaves: psicologia hospitalar; acolhimento; sala de observação.
\end{abstract}

HEALTH PSYCHOLOGY: THE HUMANIZED RECEPTION OF PATIENTS IN THE OBSERVATION ROOM OF A PRE-HOSPITAL UNIT

\section{ABSTRACT}

This article present experiments, interventions and outcomes of a curricular internship in Health Psychology performed by a senior Psychology student in a pre-hospital unity. Psychological services covered the following participants: patients, families, caregivers and crew who were between seven (7) and 82 (eighty two) years old. The Psychological Diagnostic Interview was used for conducting the experiment. The results showed that people in treatment had a positive reception of the overall care their received through the insertion of the psychology intern in the observation room. In many occasions when there was psychological intervention, not only did people feel relieved but could also

Freitas, C. R. de, \& Moretto, C. C. (2014). Psicologia da saúde: o acolhimento humanizado na sala de observação de uma unidade pré-hospitalar. 
reflect more on what is means to be sick. In this way, it was noticed a more humanized care to people in a hospital setting, where sometimes the physiological aspects might overcome all other dimensions of being human. Humanizing, thus, meant to benefit people in treatment with comprehensive care.

Key words: hospital psychology; reception; observation room.

PSICOLOGÍA DE LA SALUD: LA SALA DE RECEPCIÓN DE OBSERVACIÓN HUMANIZA DE UNA UNIDAD PRE-HOSPITALARIA

\section{RESUMEN}

En este artículo se describe la experiencia de prácticas en Psicología de la Salud de un estudiante graduado en el curso de Psicología que se llevó a cabo en una unidad prehospitalaria de una ciudad en el Estado de São Paulo. El proyecto llevado a cabo por el aprendiz cubría la atención psicológica a los pacientes, familiares, cuidadores y equipo técnico con edades comprendidas entre los 7 y 82 años de edad. Los objetivos de este proyecto comprende, básicamente, aceptar, escuchar y orientar a los pacientes, familiares, cuidadores y esquipo técnico. El instrumento utilizado para la realización de las sesiones fue la entrevista de diagnóstico psicológico. Los resultados mostraron que las personas atendidas respondieron positivamente al cuidado en generalizado que les fue destinado por la inserción de un interno de la psicología en la sala de observación. En muchas ocasiones cuando no había intervención psicológica, las personas atendidas se sentían aliviadas de su sufrimiento, así como una reflexión mayor sobre el "estar enfermo”. Se formó de esta manera, una atención humanizada para las personas atendidas en el ambiente hospitalario, donde, a veces el cuerpo físico tiene mayor atención. Humanizar significo beneficiar las personas atendidas cuidándolas integralmente.

Palabras clave: psicología de la salud; alojamiento; sala de observación.

A prática psicológica no âmbito da Psicologia da Saúde vem se estabelecendo de acordo com as mudanças nos conceitos de saúde e doença. Segundo Baptista e Dias (2012), em 1948 houve uma mudança no conceito de saúde, passando de ausência de doença para um estado de completo bem-estar físico, mental e social (Organização Mundial da Saúde), ampliando a concepção de saúde. No entanto, ponderando-se que esse estado de completude seja utópico, concebe-se doente aquele que tem uma interrupção no alcance do seu bem estar. Além disso, a saúde não deve ser tomada como ausência de sintomas, posto que um indivíduo pode se encontrar enfermo sem demonstrá-los, ratificando-se que o ser humano deve ser avaliado de forma multideterminada. A nova compreensão de saúde surgiu também a partir do crescimento dos custos da assistência à saúde, da extensão dos serviços de saúde à comunidade e do aumento da capacidade crítica nas instituições de saúde (Baptista \& Dias, 2012). Nesse

Freitas, C. R. de, \& Moretto, C. C. (2014). Psicologia da saúde: o acolhimento humanizado na sala de observação de uma unidade pré-hospitalar. 
sentido, Ismael (2006) sugere que a Psicologia tem muito a contribuir no cenário da promoção da saúde quando esclarece que

a Psicologia precisa reconhecer seu potencial de contribuição no controle da doença e na promoção da saúde física. A Psicologia é a ciência cujo objeto de estudo inclui a análise, predição e a modificação dos fatores que afetam o comportamento. Dentre as diversas áreas de estudo a Psicologia da Saúde tem sido definida como um agregado de contribuições específicas das áreas, educacional, científica, profissional e, porque não dizer, institucional. Visa à promoção e à manutenção da saúde física e emocional, a prevenção e o tratamento das doenças e a identificação de correlatos etiológicos e diagnósticos de saúde. Em um sentido mais abrangente pode promover ainda, a análise, formação e melhoria do sistema de saúde. (p. 17-18).

Um dos maiores desafios dos profissionais de Psicologia, implicados socialmente com os fatores que cercam o adoecer humano, é a superação da prática clínica em favor da disseminação de um fazer psicológico contextualizado e com olhar global para o indivíduo. Nessa perspectiva, Ismael (2006) problematiza a precariedade da saúde de nossa população, considerando que ter saúde é um privilégio para poucos. Portanto, conceitua

um dos objetivos do psicólogo que atua na área hospitalar é tentar minimizar o sofrimento do paciente e de sua família. O trabalho é focal, centrando-se no sofrimento e nas repercussões que o paciente sofre com a doença e a hospitalização, associado a outros fatores como história de vida, a forma como ele assimila a doença e seu perfil de personalidade. (p. 18).

No que diz respeito ao cuidado integral do indivíduo em um ambiente hospitalar, não se pode esquecer que o ser humano tem a sua compreensão sobre sua doença, a partir de sua vivência. Assim como destacam Bianchini e Dell’Aglio (2006), “este novo olhar humanizado permite que o paciente, ao chegar ao hospital, traz consigo, além da doença, sua história de vida” (p. 430).

Este artigo tem o objetivo de produzir conhecimento científico na área da saúde mental apresentando as experiências, intervenções e os resultados do estágio curricular em Psicologia da Saúde: Intervenções Clínico-Institucionais, realizado por uma estudante do décimo semestre do curso de Psicologia em uma unidade pré-hospitalar. Como se trata de um relato de experiência profissional, será empregada a primeira pessoa do singular nas descrições que compõem este estudo. 


\section{MÉTODO}

Participaram deste estudo pacientes, familiares, acompanhantes e equipe técnica com idades entre sete e 82 anos de idade. A fim de aceder às pessoas atendidas no ambiente hospitalar, a técnica considerada apropriada para o contexto foi a entrevista psicológica diagnóstica, que de acordo com Bleger (1998)

é sempre uma experiência vital muito importante para o entrevistado; significa, com muita freqüência, a única possibilidade que tem de falar o mais sinceramente possível de si mesmo com alguém que não o julgue, mas que o compreenda. Dessa maneira, a entrevista atua sempre como um fator normativo ou de aprendizagem, embora não se recorra a nenhuma medida especial para conseguir isso. Em outros termos, a entrevista diagnóstica é sempre, e ao mesmo tempo, em parte, terapêutica. (p. 40)

Ao se entrevistar as pessoas atendidas se percebia que se configurava a interação entre entrevistadora e entrevistados(as) no sentido de que se pode interpretar e intervir, fazendo-se correlações entre aquilo que foi comunicado e priorizando o benefício aos entrevistados/as (Bleger, 1998). Além disso, tendo em vista a fragilidade emocional das pessoas atendidas, criou-se, primeiramente, um espaço fortalecedor, a fim de que pudessem se sentir, minimamente, encorajadas a usufruir do atendimento psicológico oferecido. Sendo assim, considerou-se que o conceito de holding foi concernente com tais objetivos, conforme Winnicott (1994) o define na entrevista diagnóstica

o consultor ou especialista não precisa tanto ser arguto quanto capaz de proporcionar um relacionamento natural e de livre movimentação dentro do setting profissional [...]. Talvez o principal trabalho que se faz seja da natureza da integração, tornada possível pelo apoio no relacionamento humano, mas profissional - uma forma de sustentação (holding). (p. 230).

\section{DESCRIÇÃO DA DEMANDA}

A referenciada unidade pré-hospitalar se caracterizava por atendimentos emergenciais, realização de exames laboratoriais e radiográficos na própria unidade, e encaminhamentos para internação em outras unidades de saúde especializadas. O horário de funcionando da unidade era em turnos de 24 horas todos os dias. O nível de atenção era ambulatorial básica e de média complexidade. A clientela era referenciada e espontânea, atendida prioritariamente em casos de urgência, caracterizando-se como um pronto socorro geral.

A sala de observação continha, aproximadamente, 22 leitos, duas alas de isolamento, uma ala de emergência e uma ala pediátrica com oito leitos aproximadamente. $\mathrm{O}$ tempo estimado de permanência das pessoas atendidas era de 12 horas. De modo geral, as pessoas eram atendidas primeiramente pelos profissionais de

Freitas, C. R. de, \& Moretto, C. C. (2014). Psicologia da saúde: o acolhimento humanizado na sala de observação de uma unidade pré-hospitalar. 
enfermagem a fim de que fossem checados sinais vitais e colhidas as informações referentes à queixa do/a paciente. Posteriormente a esta avaliação, o(a) médico(a) de plantão daria continuidade ao atendimento receitando medicamentos a serem ministrados e procedimentos a serem realizados pelos profissionais da enfermagem.

De acordo com uma entrevista com a coordenadora da unidade hospitalar, a estagiária foi informada que poderia agir, efetivamente, na sala de observação da unidade. Neste local, segundo a coordenadora, os pacientes necessitavam de maior acolhimento devido ao tempo que permaneciam em recuperação e aguardando remoções para outras unidades de internação.

Conforme a estagiária foi se apropriando do campo, percebeu que o trabalho a ser feito na unidade se referiria, substancialmente, ao acolhimento humanizado aos pacientes, acompanhantes, familiares e equipe técnica. Esse acolhimento pode ser definido como a aceitação das pessoas tais como são e a receptividade para com as limitações físicas, emocionais e sociais que viessem a apresentar. A sensação de fragilidade e vulnerabilidade das pessoas, suscitadas pelo ambiente hospitalar, solicitava ações como escutar, compreender e orientar, com o propósito de amenizar sofrimentos, temores e dificuldades frente à hospitalização.

\section{PROCEDIMENTO}

O estágio se efetivou por meio de visitas semanais, num total de dez visitas, à instituição hospitalar, com duração de três horas de permanência na sala de observação da unidade. O espaço terapêutico se promoveu, essencialmente, pela escuta psicológica aos pacientes, familiares, acompanhantes e equipe técnica, considerando-se o que explicita Cardinalli (2004) sobre o adoecer

Vê-se que a doença e a saúde estão orientadas, ao mesmo tempo, pelo poder realizar e pelo ser livre, isto é, pela habilidade do homem de realizar seu existir e pelo comportamento mais ou menos livre diante do que encontra. Na doença, ocorre uma privação mais acentuada de realizar livremente seu existir, enquanto na saúde, esse realizar se mostra pelo poder dispor mais livremente das possibilidades de relação que se apresentam na abertura do mundo de uma pessoa específica (p. 99).

Os atendimentos ocorreram de forma dinâmica, sendo a disponibilidade da estagiária o disparador para o acolhimento. Portanto, de acordo com a demanda e a solicitação da equipe técnica, a atuação se deu no momento que se apresentou a necessidade. 


\section{RESUltados E Discussão}

No primeiro dia em que estive na unidade para a primeira conversa com a responsável técnica, iniciei minha investigação acerca das demandas da unidade, tendo em vista que tive que esperá-la fora da sala de observação e, posteriormente, em seu interior. Durante um período de aproximadamente três horas percebi que havia pouca comunicação entre as pessoas da equipe técnica, tão pouco se comunicavam com os pacientes, familiares e acompanhantes, movimentando-se de forma dinâmica.

Em dado momento, encontrava-me sentada nos bancos do corredor do lado de fora da sala de observação, quando fui abordada por uma senhora, a qual acompanhava o esposo ferido em um acidente doméstico. Ainda lá também estavam duas irmãs, as quais acompanhavam o pai que estava com pneumonia e aguardava transferência para outra unidade a fim de receber uma transfusão de sangue.

Durante alguns instantes de diálogo com a senhora e as irmãs, pude perceber a sensação de desamparo e desespero na qual se encontram familiares e acompanhantes quando precisam esperar por notícias sobre o estado de seus entes queridos. Desamparo e desespero estes que se referem à possibilidade de pensar na finitude daqueles que se ama, à frustração de não se poder fazer nada diante dos fatos como a morte, e da constatação da doença que necessita de tratamento contínuo.

Em outro momento, quando me apresentei a um dos membros da equipe técnica, informei-me das dificuldades que enfrentam através de seu apontamento sobre o benefício da presença de uma estagiária de psicologia na unidade; benefício que se referiria a ter alguém que pudesse ouvir as pessoas atendidas e sua família. O membro da equipe ainda compartilhou que achava pertinente que um profissional de psicologia pertencesse à equipe interdisciplinar. Além disso, afirmou que o trabalho que realiza se remete enfaticamente aos cuidados da esfera física das pessoas atendidas. Ainda assim, o membro declarou ser pertinente que a unidade tivesse uma equipe multiprofissional para principalmente os profissionais de enfermagem, a fim de oferecer suporte para as variadas demandas que se apresentam, pois "não conta de tudo" (sic).

Dentro do ambiente hospitalar, na maioria das vezes a equipe técnica, devido à demanda de trabalho, não tem condições de abarcar o pedido de ajuda emocional dos pacientes. Tendo em vista esse panorama e baseada no modelo de assistência psicológica às gestantes de Baptista e Dias (2012), coube-me ser uma agente facilitadora nas relações entre equipe técnica e paciente/família. Desse modo, a atuação envolveria orientar quanto aos fatores de riscos psicológicos presentes no contexto hospitalar, facilitando as inter-relações, planejar estratégias terapêuticas conjuntas para melhor atingir os objetivos de assistência aos pacientes e oferecer suporte psicológico aos membros da equipe quando necessitassem.

Sendo assim, ao longo do período em que se deu o estágio, as ações que se realizaram podem ser definidas como dialogar com os pacientes, familiares e acompanhantes, a partir da solicitação da equipe técnica quando percebia a necessidade desse contato, assim como pela atitude ativa da estagiária de se aproximar dessas pessoas e oferecer o atendimento psicológico que abrangia conhecer suas histórias de vida, ouvir suas angústias frente à hospitalização, esclarecer possíveis dúvidas sobre os

Freitas, C. R. de, \& Moretto, C. C. (2014). Psicologia da saúde: o acolhimento humanizado na sala de observação de uma unidade pré-hospitalar. 
diagnósticos, realizar encaminhamentos para psicoterapia individual, plantões psicológicos e CAPS (Centro de Atenção Psicossocial), sugerir atitudes que promovessem a educação para a saúde, como por exemplo, fazer boa alimentação, atividade física e priorizar algum tempo para o lazer.

Em relação a ações voltadas à equipe técnica, pode-se citar o compartilhamento de percepções sobre o paciente e seus familiares e acompanhantes, que poderiam fortalecer o vínculo entre eles, assim como o diálogo entre equipe técnica e estagiária, que promovia o autoconhecimento, principalmente no tocante à culpa, frustrações e impotência, sentimentos comuns entre os membros da equipe técnica.

De acordo com o avanço do estágio, fui percebendo de forma mais incisiva, o quanto a atuação do psicólogo no ambiente hospitalar amenizava o sofrimento e modificava o modo de olhar para o ser humano, como por exemplo, quando uma senhora depois de ser atendida pela estagiária, verbalizou que se sentia muito melhor do que quando chegara, ao ponto de complementar dizendo que o fato de ter conversado comigo naquele momento fora crucial para que não desistisse de sua vida e que ninguém até aquele momento tinha demonstrado se importar com ela, como a estagiária havia feito.

Os critérios para a avaliação dos benefícios das ações realizadas às pessoas atendidas pela estagiária foram, em sua maioria, a resposta positiva das pessoas atendidas, assim como mudanças no quadro de demanda inicial, como no caso de um casal que conseguiu ter um diálogo um pouco mais aprofundado pelo fato da estagiária ter mediado a conversa, sendo que quando chegaram o motivo principal que os levou até á unidade foi uma briga entre casal, desencadeada pela falta de diálogo que deflagrou na vertigem do marido.

Ao observar o atendimento despendido por uma das enfermeiras a duas crianças, percebi sua dificuldade em considerar o sofrimento, medo e dor das crianças devido à hospitalização. Isso pode ser percebido porque em momento algum ela conseguiu brincar com as crianças para poder deixá-las mais calmas para injetar-lhes medicamento, assim como não conversou com elas sobre os procedimentos. A dificuldade da enfermeira se encontrava em não conseguir se sensibilizar com o pavor das crianças frente a uma injeção, ou seja, parecia agir como se estivesse interagindo com as crianças mecanicamente, sem respeitar sua fragilidade emocional, devido principalmente ao seu estágio de desenvolvimento.

Acredito que o trabalho em um hospital seja muito desgastante para as enfermeiras, entretanto, isso não deveria as eximir de ter a premissa de que atuam com seres humanos fragilizados. Dessa maneira, inferi que a própria instituição hospitalar se encontrava adoecida, pois os funcionários não estavam sendo cuidados para que pudessem desempenhar um trabalho mais humanizado. Nesse sentido, Ismael (2006) explicita

É ilusório pensar que o tratamento é sempre visto pelo paciente como uma experiência benéfica e desejável. A literatura sugere amplamente que tratar a doença implica uma série de ameaças: à integridade física, à autoimagem (muito relevante no caso de cirurgias, principalmente as mutiladoras), ao equilíbrio 
emocional e ao ajustamento a um novo meio físico e social. O ambiente hospitalar, o tratamento e a manipulação do paciente por pessoas desconhecidas agridem-no tanto física quanto emocionalmente. (p. 19).

As instituições de saúde possuem dificuldades para prestar um atendimento humanizado e integral aos pacientes, que vão desde as estruturais, até ausência de equipe multidisciplinar. Evidenciou-se essa carência no que se referiu à prestação de serviço e cuidados despendidos a pessoas em situação de vulnerabilidade social, como um morador de rua. Nesse caso, durante o período que ocorreu o atendimento ao paciente, não visualizei em momento algum a presença de um médico que o examinasse, sendo que o mesmo apresentava um ferimento na cabeça, que foi examinado pela equipe técnica superficialmente através de olhares e toques, mas não se realizou curativos.

Além disso, a equipe técnica relatou outras situações de atendimento correlatas em negligência efetuadas por médicos, como por exemplo, o fato dos médicos, quando se trata de paciente que seja morador de rua, examiná-los superficialmente, concluindo que não possuem nenhuma enfermidade, que necessite de tratamento, a não ser um medicamentoso, não fazendo encaminhamentos a outros órgãos que prestem atendimento em saúde mental, posto que a unidade pré-hospitalar não conte com uma equipe interdisciplinar e não trabalhe de forma multiprofissional. Nesse sentido, Ismael (2006) assinala que o cuidado com a saúde da população envolve vários aspectos, e

Nós temos visto, com o decorrer dos anos que, apesar de a alta tecnologia médica ocidental estar realizando grandes prodígios nos campos da cura e do diagnóstico, esse esforço não é suficiente para garantir a saúde da nossa população. O que temos observado, ainda, é que essas técnicas de diagnósticos fazem dos [sic] médicos [sic] grandes especialistas que não tem tempo mais de OUVIR seu paciente na sua totalidade. Tratar é indiscutivelmente necessário, mas é preciso mobilizar na população uma mentalidade de responsabilidade individual na saúde e na prevenção das enfermidades. O profissional deve manter a compreensão exata dessa questão e avaliar dados subjetivos do paciente, podendo assim contribuir para que haja aderência ao tratamento médico e que ele possa participar ativamente do processo de hospitalização. No processo de reabilitação do paciente, é preciso incentivá-lo a investir na qualidade de vida, mesmo que para isto seu estilo de vida tenha de ser modificado. É necessário ajudar o paciente a recuperar as suas funções de acordo com sua forma de existir e ser. (p. 19)

Moretto (2007) também esclarece que a nova política em saúde mental se propõe

transformar o modelo assistencial e construir um novo estatuto social, mas ainda esbarra em muitas dificuldades para sua realização. A garantia dos direitos das pessoas com sofrimento psíquico, levando em conta os princípios e diretrizes do 
SUS e a luta por um novo modelo de assistência, propõe a criação de uma rede de serviços de atenção psicossocial, de base comunitária. (p. 8).

Em relação ao trabalho da equipe técnica no que se refere ao modo mecânico como tratam as pessoas atendidas na unidade, refletiu-se sobre a possibilidade de haver uma avaliação com base em reincidências e satisfação dos usuários do serviço. Essa avaliação poderia ser realizada tanto pelos próprios membros da equipe técnica, quanto pelos membros da gestão institucional, no intuito de ressignificar as práticas à luz, por exemplo, do que propõem Mello e Ravagnani (2009) sobre o humanizar:

A utilização do termo amenização é uma provocação, uma vez que a expressão humanizar dá a entender que o problema está naquilo que não é humano. Todavia, a postura mal humorada, agressiva e descompromissada faz parte dos valores humanos. Podem não ser positivos estes valores, mas ainda sim são humanos. Portanto, a questão não é focar a inexistência de humanidade e buscar humanizar, mas sim observar o que faz a humanidade expressar muitas vezes o seu lado nocivo. Serão as condições físicas do hospital? Será a forma de se relacionar dentro da equipe? Será a ausência de educação para a saúde junto á população? Será a corrupção que faz com que os aparelhos públicos de atendimento ainda sejam precários em sua grande maioria? O que propomos é o reconhecimento de que o ser humano é capaz de agir para o bem e para o mal, mostrando que agir positivamente é um caminho mais nutritivo. Amenizar, neste sentido, é tornar o ambiente, e as relações que nele acontecem, mais propícios ao bem estar e ao cuidado de quem é paciente e cuidador. (pp. 65-66).

No decorrer dos atendimentos, pude entrar em contato com a relutância de algumas pessoas em enfrentar suas realidades, fazendo com que atentem contra a própria vida, como foi o caso de uma paciente que chegou à unidade porque havia tentado suicídio. A jovem relatou que desejava "dormir para sempre” (sic), porque não mais suportava seu trabalho no qual sua função era de ouvir reclamações o dia todo, entretanto dependia dele para sustentar seus três filhos, os quais são de sua responsabilidade desde que se separou do pai das crianças, o qual não comparecia com nenhuma ajuda financeira.

Além disso, contou que não tinha muita paciência com os filhos e que sentia muita falta do ex-companheiro, mesmo declarando que possuía um relacionamento conturbado com o mesmo, o que gerava a sensação de desprazer contínuo para com sua própria vida. Parecia que a jovem não possuía recursos psíquicos para lidar com a solidão, a responsabilidade parental de três filhos pequenos e a falta de instrução escolar, sendo esta última a causa da falta de perspectiva e tentativa de angariar um trabalho compatível com suas potencialidades e que a deixasse mais satisfeita. Esse tipo de atitude pode se relacionar com o que Cardinalli (2004) esclarece: "Denomina-se incidentes patogênicos aquelas ocasiões que motivam uma pessoa a restringir suas possibilidades de relação consigo mesmo, com as pessoas e com o mundo” (p. 89).

Freitas, C. R. de, \& Moretto, C. C. (2014). Psicologia da saúde: o acolhimento humanizado na sala de observação de uma unidade pré-hospitalar. 
O modo retraído e de poucas palavras pelo qual se mostrava a paciente na interação com a estagiária pode conceber o que Ismael (2006) retrata: “o período de hospitalização incita o paciente a ficar mais introspectivo e passar para um processo de reavaliação de vida e de valores” (p. 26). Isto é, a jovem expressava se sentir envergonhada diante da tia e da mãe, negando que tivesse ingerido uma quantidade expressiva de medicamentos para dormir; entretanto, a tia confirmou que a encontrou desfalecida no interior de sua residência e que chamou socorro a tempo de salvá-la. Sendo assim, a paciente estava vivenciando a sensação de "nascer de novo", pois poderia ter falecido com sua atitude.

Nesse sentido, o acolhimento oferecido pela estagiária à paciente faz referência a uma das possibilidades de atuação do psicólogo hospitalar descrito por Ismael (2006), ou seja, de "tentar conhecer um pouco de sua história de vida e de sua doença. É ele quem irá procurar o paciente, oferecer ajuda a ele e ficará disponível para sua família” (p. 25). Portanto, a partir da informação colhida com equipe técnica sobre por que havia uma paciente na sala de isolamento, fiquei sabendo de que se tratava de uma paciente suicida, para qual rapidamente, a equipe técnica sugeriu que fosse despendido atendimento psicológico. Quando adentrei a sala, a paciente se encontrava um tanto sonolenta, portanto iniciei o atendimento dialogando com a tia, orientando-a sobre a necessidade de muito apoio da família naquele momento para com a paciente, posto que estivesse vivenciando um momento muito traumático em sua vida, além de que os filhos pequenos poderiam também estar se sentindo desamparados. O diálogo também se estendeu para com a mãe da paciente com igual teor.

Quando a irmã da paciente chegou para vê-la, fora orientada que sua presença e apoio seriam fundamentais nesse momento para a irmã. Além disso, quando a paciente se encontrava um pouco mais consciente e aberta ao diálogo verificou-se o conhecimento e a disponibilidade para o encaminhamento à psicoterapia individual. De forma geral, o atendimento abarcou a família no intuito de criar uma rede apoio para a paciente, tendo em vista que a tentativa de suicídio denunciasse o sentimento de desamparo da paciente.

Diante do quadro de vulnerabilidade emocional em que se encontrava a paciente, a família não mostrou acolhimento nem compreensão. A mãe e a irmã da paciente não pareciam preocupadas em animá-la, por meio de enaltecer seus aspectos positivos. Muito pelo contrário, cobravam responsabilidade de sua parte. A probabilidade de superação dessa fase aflitiva da vida da paciente parecia diminuir.

Kübler-Ross (1996), descrevendo sua experiência com pacientes terminais, esclarece que a doença de um ente da família faz com que haja uma reorganização e adaptação da família para lidar com essa realidade. Muitas vezes, os familiares acabam assumindo papéis que até então não lhes era de costume, isso causa muito desconforto e angústia. Da mesma forma, o paciente tende a absorver o clima familiar perante sua doença, assim como afirma a autora: "no período da doença, os familiares desempenham papel preponderante, e suas reações muito contribuem para a própria reação do paciente" (p. 171). Diante desse panorama, incluir a família das pessoas atendidas na rede de atenção e cuidados contribui para humanização do atendimento no ambiente hospitalar.

Freitas, C. R. de, \& Moretto, C. C. (2014). Psicologia da saúde: o acolhimento humanizado na sala de observação de uma unidade pré-hospitalar. 
Houve uma paciente que me mobilizou, pelo fato de que seu estado emocional conturbado lhe obrigava a observar seus limites, ao ponto de descrever que seu coração quase teria parado de funcionar. Nesse sentido, Baptista e Dias (2012) esclarecem que "existem pesquisas que sugerem, por exemplo, que o estresse elevado pode contribuir para o aumento da pressão arterial e influenciar os batimentos cardíacos” (p. 7). A paciente demonstrava não enxergar possibilidades menos frustrantes de encarar sua realidade, pois seu único filho havia se casado e deixado de morar com ela. Nessa perspectiva, a atuação da estagiária, por meio do acolhimento, pode promover um espaço para a reflexão, a fim de que a paciente pudesse sentir que ainda não se chegou ao fim. Desse modo, Ismael (2006) explicita os alcances da entrevista psicológica:

Sendo assim, a relação de ajuda é valorizada em si mesmo. Existe empatia, solidariedade e cooperação por parte do profissional. A entrevista pode ser o meio pelo qual o paciente pode expressar seu problema. A relação de ajuda é profissional, na qual uma pessoa deve ser assistida para operar seu ajustamento pessoal a uma situação à qual ela não se adaptava normalmente. O psicólogo deve compreender o problema nos termos em que se coloca para o paciente e ajudá-lo a evoluir pessoalmente na sua melhor adaptação. Na visão de Rogers, que defende a entrevista centrada no paciente que pode se enquadrar no setting hospitalar: o psicólogo deve ter atitude de interesse aberto, ou seja, estar totalmente disponível e agir de forma que promova a expressão espontânea do outro, atitude não de julgamento, que tudo ouve sem críticas, procurar não ser diretivo, mostrar intenção de realmente compreender o outro, de descobrir o universo subjetivo e sempre ser objetivo.... É essencial ter uma orientação positiva para captar a atenção como ela é, estar atenta a expressão direta de estados afetivos do paciente. (p. 30).

Tendo a paciente afirmado que até aquele momento de hospitalização não havia se dado conta de que sua saúde emocional estava tão debilitada, acredito que pelo modo com que se deu o encontro entre nós, permeado por empatia e compreensão que promovessem a busca pelo autoconhecimento e cuidado de si da parte da paciente, pode-se ter desencadeado o processo citado por Ismael (2006):

A primeira entrevista bem conduzida no ambiente hospitalar e o posterior seguimento do paciente também podem resultar na sua mobilização a uma continuidade do atendimento psicológico, pós-alta hospitalar, para que seja possível dar continuidade ao trabalho iniciado no hospital. É no momento de fragilidade trazida pela doença que se pode sensibilizar o paciente a se conhecer melhor e a cuidar da sua saúde emocional. (p. 32).

Ao acolher uma paciente de 82 anos que procurou atendimento na unidade devido à elevação de sua pressão arterial, pude comprovar que o modo pelo qual se encara a vida é o que estabelece, às vezes, ter-se ou não saúde. A senhora explicitou que vivia um dia de cada vez, sem guardar rancores e exercia o ato de perdoar,

Freitas, C. R. de, \& Moretto, C. C. (2014). Psicologia da saúde: o acolhimento humanizado na sala de observação de uma unidade pré-hospitalar. 
principalmente, em razão de sua religiosidade. A filha da paciente, com bem menos idade, expressava mais ansiedade e parecia necessitar mais de cuidados do que a mãe. Diferentemente da mãe, a filha demonstrava dificuldades em aceitar e respeitar as escolhas alheias, bem como a forma autônoma de viver da mãe. Nesse sentido, o modo de ser saudável da paciente, pode ser compreendido a partir do que preconiza Pompéia e Sapienza (2011):

Apropriar-se de seu ser livre é também poder ser livre para obedecer a si mesmo, numa fidelidade ao seu caminho que se desdobra no tempo; para comprometerse com o mundo, na correspondência às oportunidades; para comprometer-se com os outros, no compartilhar o ser livre dos homens. (p. 29).

A forma pela qual um enfermeiro descreveu sua profissão como algo "mecânico" (sic), pareceu denunciar uma falta de apropriação de suas próprias potencialidades, limitando-o e o fazendo se sentir desvalorizado. Esse tipo de comportamento se faz comum nos ambientes hospitalares onde não se valoriza, muitas vezes, nem mesmo o cuidado despendido aos próprios pacientes. Nessa perspectiva, Mota, Martins e Véras (2006) explicitam aspectos os quais atravessam a postura do integrante da equipe clínica:

Muitos profissionais de saúde submetem-se, em sua atividade, a tensões provenientes de várias fontes: contato freqüente com a dor e o sofrimento e com pacientes terminais, receio de cometer erros, relações com pacientes difíceis. Sendo assim, cuidar de quem cuida é condição suficiente para desenvolver projetos de ações em prol da humanização da assistência. (p. 324).

Em dado atendimento, o comportamento desesperado e os gritos de um paciente frente às dores no peito e à falta de ar que dizia sentir, chamou atenção de todos os presentes. A estagiária acabou por entrar em contato com a possibilidade de presenciar um óbito no hospital. O "incômodo" que o paciente cardíaco estava causando fazia com que a equipe técnica se comportasse como se o paciente estivesse "exagerando". Entretanto, perceberam que ele realmente precisava de cuidados médicos urgentes.

Quando questionada sobre o estado do paciente, uma das enfermeiras declarou que o caso era grave e com suspeita de edema. Acredito que o paciente não estava em condições físicas para conversar sobre questões emocionais. Em relação à postura displicente despendida pela equipe técnica ao paciente cardíaco, Balduino, Mantovani e Lacerda (2009) mostram uma forma diferente de cuidar do portador de doença crônica cardíaca:

É possível observar que o cuidar humanizado torna-se indispensável ao enfermeiro, que deve ir além do estudo de caso e tratar o paciente não como um mero objeto do processo de cuidar, visto que, como profissional, precisa transcender o cuidado propriamente dito, apresentar a capacidade de compreensão de quem é esse paciente, o que o levou ter a doença. A 
implementação das ações do cuidado no dia-a-dia do enfermeiro implica, também, perceber o paciente como um ser total, respeitar seus valores, crenças, sentimentos, emoções, e não apenas considerar o aspecto biológico. (p. 344).

Houve um casal que solicitou muita atenção e acolhimento da estagiária. O paciente e esposo demonstrava muito sofrimento e descontrole frente à percepção de que sua mulher estava buscando resgatar sua individualidade. Apesar de a esposa ter concebido o relacionamento como desgastado, mostrava dificuldade de se posicionar firmemente em relação aos seus desejos. O marido, por sua vez, desesperava-se frente à possibilidade de ter que viver em função de si e não do outro. Além disso, não pareceu possuir, no momento, condições emocionais para refletir sobre as limitações de seu modo ser.

A esposa relatou que se dirigiram até a unidade devido a um desentendimento entre o casal que culminou no abalo da estrutura física e emocional do marido, a ponto de ele tremer muito e ter dificuldades para se locomover. A principal causa da briga fora a falta de comunicação entre eles. Os resultados encontrados no estudo de Guimarães (2009) apontam para as consequências da falta de comunicação entre casais:

A falta de comunicação, ou a alteração em sua forma de expressão, pode gerar sentimentos diversos nos indivíduos que a vivencia. Os participantes deste estudo descreveram sentirem-se agredidos, ignorados, e, em alguns casos, desprezados pelo companheiro, por não serem compreendidos e, tampouco, ouvidos. Em seus relatos constatou-se que os sentimentos descritos acima, para alguns, são mais dolorosos do que a violência física. Relataram ainda que a violência não visível esteja permeando a relação, fator que provoca vários danos psíquicos, como a baixa autoestima, sentimento de inferioridade. (p. 28).

O que se revelou como diferencial nesse atendimento foi o estabelecimento de um setting no contexto hospitalar, onde a atuação da estagiária se caracterizou enfaticamente, pela mediação. Isto mostra o quanto o profissional psicólogo no hospital se expõe à complexidade do fenômeno humano. Desse modo, busca em seu arcabouço profissional vivenciado, a opção compatível para lidar com determinada situação que se apresenta, tendo sensibilidade, no momento em que atende, para perceber a necessidade do paciente. A fim de minimizar o sofrimento e o conflito do casal, a postura da estagiária se pautou, analogamente, ao que descreve Lazzaretti (2007) sobre a concepção humanista-existencial como uma das abordagens teórico/clínicas que podem fundamentar o trabalho em Psicologia Hospitalar:

Quando a relação é estabelecida, o psicólogo consegue ajudar o paciente a se ver e rever no mundo, como um ser que possui potencialidades, para mudar ou aceitar como realmente é. (...). O psicólogo hospitalar deve trabalhar o sintoma, que significa trabalhar o real e o irreal da pessoa. O sintoma como resistência múltipla (físico-mental) se coloca entre o desejo e a proibição, porque ele surge como solução provisória de uma ansiedade maior. O psicólogo deve saber 
respeitar a resistência, pois ela pode indicar que o paciente ainda não tem suporte suficiente para entrar em determinados conteúdos. Não é necessariamente uma patologia, mas uma forma de relacionar-se com o mundo. O ser humano deve ser considerado como um todo, um ser que é biológico, com corpo e mente e que vive em sociedade. A psicoterapia procura levar o cliente em direção à mudança, seja na forma de agir, pensar, sentir ou a aceitar a realidade como realmente é. (p. 37).

O atendimento despendido a um determinado paciente fez com que a estagiária vivenciasse a pluralidade de demandas inerentes ao ambiente hospitalar. Compreendeuse, sem maiores necessidades de diagnóstico psiquiátrico, que o paciente chegou à unidade com a cabeça machucada. Durante todo o tempo em que estive na unidade, não presenciei nenhum médico examinar seu ferimento na cabeça, a não ser os enfermeiros, que o fizeram superficialmente.

O paciente estava desorientado e tinha um discurso desconexo. Por ter verbalizado muito pouco sobre sua vida e sobre o ferimento, a equipe técnica, tanto quanto a estagiária, sentiram dificuldades em ajudar o paciente como o mesmo merecia. Contudo, por se saber que o paciente era morador de rua, quando questionado sobre se sentia fome e se gostaria de tomar banho, o paciente assentiu e teve essa necessidade atendida.

O enfermeiro que o atendeu desde quando chegou estava nervoso diante do comportamento do paciente, parecendo não saber lidar com ele. A estagiária se sentiu angustiada e impotente por tentar identificar os motivos que levaram o paciente a vir até o hospital, além do machucado na testa. Nesse sentido, Mion e Schneider (2003) apontam resultados da aceitação e percepção de profissionais que trabalham em hospitais gerais sobre a implementação de leitos psiquiátricos na instituição que atuavam, tais como

(...) os profissionais não se sentem preparados para atender a clientela com transtorno mental. Esta questão era percebida enquanto enfermaria de hospital geral, onde a equipe multidisciplinar ao deparar-se com paciente portador de patologia psíquica, não se sentia à vontade para lidar com esta clientela, e estas falas evidenciam que o despreparo da equipe constitui-se em um problema para a implantação de leitos psiquiátricos em hospital geral. Todos os discursos falam que seria viável a implantação destes leitos, desde que houvesse treinamentos e reciclagem para a equipe que atuaria junto ao doente. (p. 40).

O paciente, pelos olhares e comentários a ele destinados pelos presentes, parecia causar medo e desconforto, principalmente por perambular pela sala de observação. Pude inferir, pelo que presenciei desde que o paciente chegou à unidade, que se ele houvesse permanecido "acomodado" na ala de isolamento, não teria sido contido fisicamente por quatro homens, após ter sido abordado rispidamente por um dos enfermeiros.

Freitas, C. R. de, \& Moretto, C. C. (2014). Psicologia da saúde: o acolhimento humanizado na sala de observação de uma unidade pré-hospitalar. 
Contudo, não se prescinde da necessidade de se prevenir a invasão do espaço do outro por parte do paciente, algo que não aconteceu, posto que sua postura estagnada ao ser solicitado, fez com que se instaurasse um movimento de precaução frente ao imprevisível. Nesse sentido, apesar de se levar em conta que a unidade não conta com uma estrutura física nem profissional para prestar um atendimento singularizado a um paciente com indícios de transtorno psiquiátrico, Mion e Schneider (2003) evidenciam em seus estudos que

Uma questão que fica explícita nestes depoimentos é a vinculação direta entre doença mental e pobreza, revelando ainda as discrepâncias na assistência à saúde, em que não se pode ter, convivendo num mesmo espaço, pessoas de diferentes níveis sociais. A inclusão de serviços de psiquiatria em hospital geral pelo que se pode observar ocorreria com uma certa resistência. Um dos fatores citados como dificultadores deste processo é o preconceito. (p. 41).

Segundo Angerami-Camon (2001), "no hospital, ao contrário do paciente que procura pela psicoterapia após romper eventuais barreiras emocionais, a pessoa hospitalizada será abordada pelo psicólogo em seu próprio leito” (p. 75). Sendo assim, o atendimento psicológico foi oferecido aos pacientes, bem como para sua família (ou acompanhantes) e estes puderam ter uma escuta diferenciada. Em um dos atendimentos, tanto a acompanhante/filha de uma das pacientes, quanto a mãe que se encontrava com seu filho adoecido, demonstraram que puderam elaborar questões emocionais que, até então, pareciam não terem se dado conta. A acompanhante/filha falou sobre sua relação com o pai que enfrenta uma depressão. A mãe que estava com seu filho adoentado pode refletir sobre como tem vivenciado seu papel de mãe e sobre a morte do marido. Nessa perspectiva, Angerami-Camon (2001) aponta que "é interessante observar que o avanço da medicina, com todo seu aparato tecnológico, não consegue prescindir do psicólogo pela sua condição de escuta das manifestações d'alma humana” (p. 78).

Notou-se pelos relatos das pessoas atendidas que o profissional psicólogo no ambiente hospitalar tende a ser um catalisador do processo de humanização, por meio da linguagem, do diálogo e do acolhimento a quem se abre para o cuidado. No que diz respeito à prática de humanizar, Angerami-Camon (2001) afirma que

Ao trabalhar no sentido de estancar os processos de despersonalização no âmbito hospitalar, o psicólogo estará ajudando a humanização do hospital, pois seguramente esse processo é um dos maiores aniquiladores da dignidade existencial da pessoa hospitalizada. Um trabalho de reflexão que envolva toda a equipe de saúde é uma das necessidades mais prementes para fazer com que o hospital perca seu caráter meramente curativo para transformar-se numa instituição que trabalhe, além da reabilitação orgânica, o restabelecimento da dignidade humana. (p. 68-69). 


\section{CONSIDERAÇõES FINAIS}

O ambiente hospitalar e o processo de hospitalização suscitam nas pessoas angústia em se deparar com a vulnerabilidade, fragilidade, dependência, limites, dor e, principalmente, com a finitude e a morte. Portanto, como estagiária e humana que sou, fui atravessada pelas mesmas questões e as considerei ao realizar meu trabalho. Também me percebi impotente tal e qual a equipe técnica em vários momentos dos atendimentos. Verifiquei que há muito a ser instituído, como políticas públicas para que se efetive um atendimento humanizado para com a população.

Os profissionais da saúde sofrem devido a uma sobrecarga de trabalho e não são cuidados, em razão do mesmo descaso com que são tratados os pacientes na rede pública de saúde. A defasagem se encontra no desprezo à reabilitação do paciente, ao seu cuidado global e à falta de uma equipe multidisciplinar. Entretanto, foi possível perceber o quanto há carência por parte da equipe técnica de se colocar no lugar do outro, proveniente da disseminação do pensamento individualista da sociedade atual e da preferência pela eficácia (maior quantidade em menor tempo) no trabalho, em detrimento da qualidade no atendimento. Além disso, o profissional não é valorizado nem ao menos financeiramente.

Por fim, pude inferir que o estágio em Psicologia hospitalar institui uma prática e percebi o quanto é importante que se abram novos postos de trabalho nessa área, haja vista que o cuidado oferecido à população atendida foi necessário para amenizar 0 sofrimento de uma gama de pessoas. Além do mais, para que as frentes de trabalho se abram é imprescindível que nossa categoria cada vez mais tente se embrenhar nesse campo, a fim de se comprovar, por meio principalmente de pesquisa, a importância da inserção do profissional psicólogo na equipe multidisciplinar das instituições de saúde.

\section{REFERÊNCIAS}

Angerami-Camon, V. A. (Org). (2001). E a psicologia entrou no hospital... (3a ed.) São Paulo: Pioneira.

Balduino, A. F. A., Mantovani, M. F., \& Lacerda, M. R. (2009). O processo de cuidar de enfermagem ao portador de doença crônica cardíaca. Escola Anna Nery Revista de Enfermagem, 13(2), 342-351.

Baptista, M. N., \& Dias, R. R. (2012). Psicologia Hospitalar - Teoria, Aplicações e Casos Clínicos (2a ed.). Rio de Janeiro: Guanabara Koogan.

Bianchini, D. C. S., \& Dell'Aglio, D. D. (2006). Processos de resiliência no contexto de hospitalização: um estudo de caso. Paidéia (Ribeirão Preto), 16(35), 427-436.

Bleger, J. (1998). Temas de psicologia: entrevista e grupos (R. M. M, Moraes, Trad., L. L, Rivera, Rev.) São Paulo: Martins Fontes.

Cardinalli, I. E. (2004). Daseinsanalyse e Esquizofrenia. São Paulo: Educ.

Guimarães, K. A. C. (2009). A dificuldade de comunicação do casal: um olhar sistêmico. Trabalho de Conclusão de Pós-graduação Latu Sensu em Terapia de

Freitas, C. R. de, \& Moretto, C. C. (2014). Psicologia da saúde: o acolhimento humanizado na sala de observação de uma unidade pré-hospitalar. 
Casais e Família, Centro de Atendimento e Estudos em Psicodrama, Universidade Católica de Goiás, Goiânia.

Ismael, S. C. (Org.) (2006). A prática psicológica e sua interface com as doenças. São Paulo: Casa do Psicólogo.

Kübler-Ross, E. (1996). Sobre a morte e o morrer: o que os doentes têm para ensinar a médicos, enfermeiras, religiosos e aos seus próprios parentes (7a ed., $\mathrm{P}$. Menezez, Trad.) São Paulo: Martins Fontes.

Lazzaretti, C. T. et al. (2007). Manual de psicologia hospitalar. Curitiba: Unificado. Recuperado de http://crppr.org.br/download/164.pdf.

Mello, F., \& Ravagnani, R. (2009). Projeto Cultural Canto Cidadão. In Caderno de Anais da VII Jornada Apoiar do Instituto de Psicologia da Universidade de São Paulo (p. 63). São Paulo, SP.

Mion, J. Z., \& Schneider, J. F. (2003). Leitos psiquiátricos em hospital geral: visão de profissionais que atuam em hospital geral. Revista Eletrônica de Enfermagem, 5(1), 38-42.

Moretto, C. C., \& Terzis, A. (2007). A humanização na área de saúde mental pública: uma revisão teórica de trabalhos com Equipes Multiprofissionais. In Anais do VIII Simpósio CEFAS e Jornada FLAPAG, p.123-130. Campinas, SP.

Mota, R. A., Martins, C. G. M., \& Véras, R. M. (2006). Papel dos profissionais de saúde na política de humanização hospitalar. Psicologia em Estudo, 11(2), 230-330.

Pompeia, J. A., \& Sapienza, B. T. (2011). Os dois nascimentos do homem: escritos sobre terapia e educação na era da técnica. Rio de Janeiro: Viaverita.

Winnicott, D. W. (1994). Explorações Psicanalíticas. Porto Alegre: Artes Médicas.

\section{Sobre as autoras:}

Cali Rodrigues de Freitas é psicóloga pela Universidade Paulista, campus Sorocaba. Cybele Carolina Moretto é doutora em Psicologia pela Pontifícia Universidade Católica de Campinas. Docente da Universidade Paulista, campus Sorocaba.

Email para correspondência com os autores: cybele.moretto@ig.br

Recebido: $14 / 03 / 2014$

Revisado: 24/06/2014

Aprovado: 10/08/2014

Freitas, C. R. de, \& Moretto, C. C. (2014). Psicologia da saúde: o acolhimento humanizado na sala de observação de uma unidade pré-hospitalar. 